los arquitectos también pueden oscilar entre estas posturas. Por eso, lo fundamental sería que los hombres todos, cualquiera sea nuestra profesión u oficio, fuéramos más humanos.

Para lograrlo, habría que cultivar áreas de las ciencias humanas, como las siguientes:

- La palabra (la lengua), como un experimento de comunicación de dos seres integrales (cuerpo y alma).

- La historia, en el sentido de dar contexto a la realidad y vivencias de ese "otro".

- Las artes, como una forma de sublimar el alma y los valores del hombre.

Como dice el profesor mejicano Ruy Pérez Tamayo, "un médico culto es mejor médico, no porque sea médico, sino porque es mejor ser humano".

Si bien existen normas, decálogos, escritos varios sobre la "ética médica", estos se corresponden más bien a la medicina, a la ciencia médica y no al médico como individuo. Este profesional debe guiarse por la "ética del médico", que no debe diferir de la ética del hombre en general. No hay médicos deshumanizados; hay personas deshumanizadas.

Debemos recordar que el núcleo central de la medicina es la relación médico-paciente, relación humana como tantas otras, como la amistad o la relación padre-hijo, con la diferencia de que el objetivo es buscar la salud, a veces, o la calma, siempre. Y, como relación humana, necesita el condimento indispensable del afecto. Hay que sumar amor a nuestro quehacer médico; el sentimiento acerca, supera barreras, ilumina, ayuda a entender la diversidad de los individuos y sus historias.

En el ejercicio cotidiano de la medicina y las competencias clínicas, puede que necesitemos más de saber escuchar y hablar. Muchas veces, será necesario poner el corazón en la partida y no solo el cerebro. Debemos despertar el interés cósmico para tener varias luces que iluminen un todo. Debemos ejercer el saber médico y el de otros en tareas interdisciplinarias y transdisciplinarias trabajando unidos, aportando cada uno lo suyo. Debemos aprender a tener una visión holística de la vida, de las personas y de sus realidades, tan variadas como únicas e importantes. Y, finalmente, debemos atesorar algo de alma de payaso para que el llanto y la sonrisa convivan en armonía, para tener una esperanza y la alegría a flor de piel, aun en los rincones más dolorosos del alma.

Dr. Héctor Pedicino

Médico pediatra y neonatólogo.

Subjefe del Servicio de Pediatría y Neonatología,

Hospital Italiano de Córdoba.

Docente universitario de la cátedra Pediatría,

Facultad de Ciencias Médicas,

Universidad Nacional de Córdoba.

Docente universitario de la cátedra

Medicina Antropológica, Facultad de Ciencias ,

Universidad Nacional de Córdoba.

http://dx.doi.org/10.5546/aap.2016.502

Texto completo en inglés: http:/ /dx.doi.org/10.5546/aap.2016.eng.502

\title{
Una propuesta para clasificar la felicidad como una enfermedad psiquiátrica
} An attempt to include happiness within the psychiatric disorders

\section{PREFACIO}

La reciente publicación del Manual Diagnóstico y Estadístico de los Trastornos Mentales (DSM-V), ${ }^{1}$ abre un abanico de nuevos criterios diagnósticos, en enfermedades de adultos y de los niños. El problema es que estos criterios son tan amplios, que hay riesgo de que una gran proporción de la población general quede incluida dentro de alguna de las enfermedades descriptas. Sobre estas bases, y a los fines de ser consecuente con dicho Manual, creí oportuno hacer el comentario de un excelente artículo de Richard Bentall de la Universidad de Liverpool. ${ }^{2}$ El artículo es más largo que este comentario, y contiene más bibliografía que la que figura aquí, pero creo dar testimonio de lo complejo de las clasificaciones, y la calificación de "enfermedad" como categoría nosológica establecida en forma apodíctica.

Las consideraciones vertidas por el Dr. Bentall están en letra cursiva. 


\section{DESCRIPCIÓN DEL ARTÍCULO}

El autor comienza diciendo que "la felicidad es una condición que no ha recibido suficiente atención por parte de psicopatólogos; por ello, la investigación al respecto es muy limitada. No obstante, las pautas encontradas en el DSM-V brinda suficiente sustento como para incluir la condición como un trastorno psiquiátrico. Si bien la comunidad de psiquiatras podría resistir esta iniciativa, los criterios diagnósticos de la felicidad serían más seguros que aquellos que permiten diagnosticar esquizofrenia, y otras condiciones".

El autor se basa en los escritos de Argyle M, ${ }^{3}$ que reconoce en la felicidad tres componentes: afectivo, cognitivo y conductual. "Dado que hay personas con felicidad en todas las culturas habría una base fuertemente biológica. Observaciones no controladas tales como las del teatro y las novelas, sugieren que la gente feliz tiene a menudo conductas descuidadas, contactos personales y recreacionales frecuentes, y muestran acciones proactivas hacia quienes no se consideran felices. En ausencia de marcadores fisiológicos, parece que el mejor criterio diagnóstico (al igual que el aplicado al dolor), es el subjetivo. Como dice Argyle "si la persona dice que es feliz ", entonces "es feliz".

"La epidemiología es poco conocida, la incidencia y prevalencia depende de los criterios diagnósticos usados, tal como ocurre con las limitaciones diagnósticas de la esquizofrenia. Así, según una encuesta del Reino Unido, el 25\% de la gente dice que "se sintió bastante bien ayer" Andrews y Whitney encontraron que solo el 5\% de adultos sentía "satisfacción en la vida". ${ }^{5}$ Adicionalmente, si las telenovelas reflejan en alguna medida la vida real, la felicidad sería algo bastante raro, tanto en Manchester, Londres como en Australia. La prevalencia depende también de las clases sociales, las personas de clases altas parecen tener más sentimientos de 'disfrutar más de la vida' que las de clases bajas".

"La etiología de la felicidad es desconocida, pero algunas teorías afirman que es consecuencia de eventos positivos de la vida, mientras que los defensores de los factores genéticos dicen que hay personas que son permanentemente más felices que otras, lo que reforzaría los fundamentos biológicos, relacionados con la autoestima, y habilidades sociales. ${ }^{3,5}$ Con respecto al ambiente, hay pocas dudas de que los episodios discretos de felicidad, se suceden después de eventos vitales positivos. Más aun, se encontraron varios centros cerebrales y sistema bioquímicos relacionados con este trastorno; la estimulación de ciertos centros cerebrales en animales produce cambios afectivos y conductuales, al igual que la administración de algunas drogas, tales como anfetamina y alcohol".

"Si la felicidad es una enfermedad o no, es una pregunta que permanece sin respuesta clara, pero haciendo una aproximación sensata, vale la pena remitirse a otras enfermedades psiquiátricas, como la esquizofrenia, el sindrome bipolar, etc. ${ }^{6} \mathrm{Al}$ igual que ellas, la felicidad puede ser concebida como una dimensión del afecto. Sin embargo, la relación entre felicidad y otras dimensiones afectivas permanece poco clara. En un análisis factorial los informes de felicidad y los de estados afectivos valorados negativamente fueron agrupados como factores diferentes, sugiriendo que pertenecen a categorías independientes".

"Es interesante saber que las personas que refieren altas intensidades de felicidad también refieren altas intensidades de otras emociones, sugiriendo que se trata de un estado neurofisiológico de desinhibición; si bien la frecuencia con que la gente refiere estados de felicidad y de emociones negativas esta inversamente correlacionada".

"Hay confusión científica entre la felicidad y la manía. A pesar de que Argyl encontró que la manía, en contraste con la felicidad, está caracterizada por excitación, los criterios de la Asociación Americana de Psiquiatría para diagnosticar hipomanía parece englobar la felicidad en este estado".

"La estimulación de lóbulo parietal puede producir sintomas de esquizofrenia en humanos, y también es posible (estimulando centros subcorticales) producir sintomas de felicidad. Pareciera que los estados emocionales positivos (eufóricos) y negativos (depresión) se generan por estimulación de centros cerebrales subcorticales que mantienen un balance. Así, los estados afectivos anormales serían la resultante de un disbalance entre ambos".

"No hay datos suficientes como para afirmar que la felicidad sea algo estadísticamente anormal, pero en caso de que esté asociado a alguna desventaja biológica, eso sí serviría para considerarla una enfermedad. Hay evidencia empírica de la asociación entre felicidad y auto-indulgencia, sobrepeso e ingesta de alcohol. Dado la asociación entre obesidad y alcohol como riesgo de salud, parece razonable asumir que la felicidad lleva a conductas impulsivas, lo que implica un riesgo moderado de muerte.

"La felicidad puede ser considerada una enfermedad también desde una perspectiva filosófica. Radden ${ }^{7}$ dice que lo que diferencia una conducta que no merece atención psiquiátrica y un trastorno psiquiátrico, es la irracionalidad de esta última. Irracionalidad sería la conducta inusual, que no lleva a una utilidad específica, que fracasa en expresar una meta definida, con contradicciones, sin sentido aparente, y falta de imparcialidad. Muchas de estas características son encontradas en los estados de felicidad. La gente feliz brinda descripciones sobrevaloradas de sus propios 
logros, y muestran opiniones irreales de su persona cuando se comparan con otros. Esto es clara evidencia de que la gente que sufre felicidad, debería ser considerada como que padece un trastorno psiquiátrico".

"Una posible objeción a la propuesta es que la felicidad no parece generar la necesidad de tratamiento, pero lo mismo puede decirse de enfermedades como la anorexia nervosa y la drepanocitosis, que solo comenzaron a reconocerse como merecedoras de un tratamiento, estando bien avanzado el siglo XX. Además el hecho de que una condición sea culturalmente aceptada como positiva es extremadamente peligrosa, corremos el riesgo de aceptar como adecuada la costumbre de algunas sectas hindúes de quemar viva a la viuda, para que acompañe en el más allá a su marido recientemente fallecido".

Sobre estas bases, el autor propone que la felicidad debería ser incluida en el DSM-V bajo un título más formal, reemplazando la palabra "felicidad" por "trastorno afectivo mayor variedad placentera.

\section{COMENTARIO} fondo:

El autor hace varios cuestionamientos de

Primero resulta notorio que haya publicado su artículo en una revista de ética médica. Es posible que piense que el problema es transdisciplinario que compromete nuestra práctica, cualquiera sea la especialidad involucrada.

Se plantea el debate sobre qué es una enfermedad. Curiosamente, los médicos rara vez nos cuestionamos esta calificación. Nos parece que las enfermedades son entidades preexistentes a la medicina, y que ésta, lo que hace es solamente descubrirlas, de la misma forma que se descubren las leyes de la naturaleza. Pero resulta que en la naturaleza no hay enfermedades, el concepto de enfermedad es una construcción social ${ }^{8}$ y sus criterios dependen de la cultura.

Una malformación en la época de los egipcios era un aviso de los dioses sobre la naturaleza excepcional del sujeto malformado que había que respetar, y una convulsión en la edad media expresaba posesión del diablo. En 1950 la homosexualidad en Argentina era mayoritariamente considerada una enfermedad, $\mathrm{y}$ ahora hay una ley de matrimonio igualitario.

Como dice el autor, hay otro criterio para definir una enfermedad que puede ser el estadístico, pero con la variación que hay en la prevalencia de gente feliz en los países ocurre lo mismo que con el síndrome de hiperactividad, que es extremadamente variable. ${ }^{6}$
El tercer criterio de que algo sea una enfermedad es que parece haber una necesidad obvia de "requerir tratamiento", pero nuevamente, aquí nos topamos con problemas relacionados con la cultura y hasta con la política. En los años ' 50 en la Unión Soviética, muchos disidentes políticos eran considerados como "enfermos mentales" e internados por disentir con el régimen.

Si podemos dar ejemplos de la influencia decisiva de la cultura, la historia, y hasta la política, en la creación de una enfermedad, también debería resultarnos fácil deducir que esos criterios pueden ser influenciados por factores económicos. En este caso el razonamiento sería: "si es redituable que algo sea una enfermedad, pues entonces reconozcámosla como tal".

Queda entonces por resolver (a mi manera de ver) el problema de las variaciones extremas de la normalidad, como por ejemplo, la estatura que está por debajo del percentil $3^{\circ}$ (que por definición debe considerarse baja estatura), o los niños demasiados tranquilos o demasiado activos, o demasiado rebeldes (recordemos el síndrome llamado "síndrome de desobediencia desafiante" así como muchas otras variaciones de la conducta humana consideradas discretas.

Al ser construcciones sociales de nuestra cultura, su categorización como "enfermedad" podría provocar que los individuos "afectados" sean tratados, excluyéndolos así de la población normal.

Dr. Horacio A. Lejarraga, D.M.

http://dx.doi.org/10.5546/aap.2016.503

Texto completo en inglés: http://dx.doi.org/10.5546/aap.2016.eng.503

\section{REFERENCIAS}

1. American Psychiatric Association. Diagnostic and Statistical Manual of Mental Disorders. $5^{\text {th }}$ ed. Washington: APA; 2013.

2. Bentall RP. A proposal to classify happiness as a psychiatric disorder. J Med Ethics 1992;18(2):94-8.

3. Argyle M. The psychology of happiness. London: Methuen; 1987.

4. Warr P. Payne R. Experiences of strain and pleasure among British adults. Soc Sci Med 1982;16(19):1691-7.

5. Campbell A. The sense of well-being in America. New York: McGraw-Hill; 1981.

6. Lejarraga $\mathrm{H}$. La venta de enfermedades. Una tendencia contemporánea a transformar a las personas en pacientes Med Infant 2013;XX(1):62-9.

7. Radden J. Madness and reason. London: George Allen \& Unwin; 1985.

8. Lejarraga A. La construcción social de la enfermedad. Arch Argent Pediatr 2004;102(4):271-6.

9. Pardini DA, Frick PJ,MoffittTE. Building an evidence base for DSM-5 conceptualizations of oppositional defiant disorder and conduct disorder: introduction to the special section. J Abnorm Psychol 2010;119(4): 683-8. 